OPEN ACCESS

Edited by:

Lawrence T. Lam

University of Technology

Sydney, Australia

Reviewed by:

Wong Yau Ho Paul,

Tung Wah College, Hong Kong,

SAR China

Yongxin $\mathrm{Li}$,

Henan University, China

*Correspondence:

Ottar Bjerkese

ottar.bjerkeset@nord.no

Specialty section: This article was submitted to

Public Mental Health,

a section of the journal

Frontiers in Psychiatry

Received: 04 July 2021 Accepted: 07 September 2021

Published: 20 October 2021

Citation:

Sæther MH, Sivertsen B and Bjerkeset O (2021) Mental Distress,

Help Seeking, and Use of Health Services Among University Students.

The SHoT-Study 2018, Norway.

Front. Psychiatry 12:727237.

doi: 10.3389/fpsyt.2021.727237

\section{Mental Distress, Help Seeking, and Use of Health Services Among University Students. The SHoT-Study 2018, Norway}

\author{
Marie Husøy Sæther ${ }^{1}$, Børge Sivertsen ${ }^{2,3,4}$ and Ottar Bjerkeset ${ }^{1,4 *}$ \\ ${ }^{1}$ Faculty of Nursing and Health Sciences, Nord University, Levanger, Norway, ${ }^{2}$ Department of Health Promotion, Norwegian \\ Institute of Public Health, Bergen, Norway, ${ }^{3}$ Department of Research \& Innovation, Helse Fonna HF, Haugesund, Norway, \\ ${ }^{4}$ Department of Mental Health, Faculty of Medicine and Health Sciences, Norwegian University of Science and Technology, \\ Trondheim, Norway
}

Background: Existing studies have documented high levels of mental distress in University and college students, complemented with poor help-seeking behavior. Colleges and universities offer a unique setting to address mental health problems that might overcome some of the most prominent barriers to help-seeking.

Objective: We aim to describe the use of campus-based health care services and health services available in the near-by community among students in Norwegian student welfare organizations. We compare health care service use between non-local (in-movers) and local students, students at large and small welfare organizations, and students with severe and medium-low levels of mental distress.

Methods: Data stem from the SHoT study (Students' Health and Well-being Study), a national survey from 2018 of all students aged 18-35 undertaking higher education in Norway. Mental distress was assessed using the Hopkins Symptom Checklist-25 (HSCL-25), and we also obtained self-report data on use of health care services. Data on health care services offered at Norwegian student welfare organizations was obtained from semi-structural telephone interviews.

Results: Non-local students used health care services that are low threshold, easily accessible and close to campus (health clinics and services organized by the student welfare organization) to a larger extent than local students. Students with symptoms of severe mental distress used almost all types of health services more than other students. We found big differences in reported use of health services in large and small organizations, yet these differences mirrored services available, and not necessarily student demand and preferences.

Conclusion: Services offered by the student welfare organizations seem to play a particularly important role for non-local students and students reporting symptoms of severe mental distress.

Keywords: higher education, mental health, health services, help-seeking, student subgroups 


\section{INTRODUCTION}

The high and increasing prevalence of mental distress and health problems in University students have become cause for concern. Cross-national studies carried out by the WHO suggest that about one third of college students have experienced mental health problems in the past 12 months $(1,2)$, and there are strong indications of a sharp increase in the prevalence among youth and students in general over the last decade $(3,4)$. For some, the period of entering higher education is a time associated with increased personal and academic stressors. In addition, students are also a high-risk population due to their age, as most lifetime mental disorders have their onset before 25 years of age $(5,6)$. For vulnerable students, the encounter with University life may therefore lead to, or worsen already existing mental health problems (7).

Surveys among students at European universities and colleges indicate that the global prevalence of mental health problems suggested by the World Health Organization (WHO) is representative of the situation in Europe, Scandinavia and Norway. Studies have been conducted at campuses in several countries, including the UK (7-9), Turkey (10), Spain (11), Norway (12), Germany (13), France (14), and Sweden $(15,16)$. Most of these studies report a prevalence of moderate to severe self-reported mental health problems as high as $30 \%$. Most students impaired by this suffer from symptoms indicative of depression and anxiety $(17,18)$. However, findings from existing studies also indicate that these students are reluctant to seek help and many do not receive adequate treatment (19). Many prefer to handle mental health challenges alone or by support from close friends and relatives (20). Further, many students experience substantial barriers to help-seeking, including fear of stigma, lack of trust in services, and costs (21).

Scholars and health workers who have studied the student population over time, state that there is an urgent need to counter the trend of increasing mental health problems among students $(22,23)$. By now, there is a growing awareness of the importance of school mental health as an aspect of health promotion (24), leading national governments and international organizations (e.g., WHO) to put children and youth's mental health on their agendas and to encourage investments in infrastructures that promote mental health in students, such as school- and University-based health services or web-based programs (25).

Colleges and universities offer a unique setting to address mental health problems among young adults and attend to them before they grow in severity and cause long-term problems. All students at Norwegian universities and colleges belong to a student welfare organization that offers a variety of services, including advisory and health care services, sports facilities, housing, and kindergartens. The membership is mandatory for all students and the organizations are, by regulation, obliged to ensure that students have access to all types of welfare services needed given the study-specific context (26). For the most part, this means supplementing local public and private services rather than supplying full-scale health care services. More specifically, to make sure students have easy access to low-threshold and free-of-charge or subsidized services to consult in the case of less urgent health problems, such as mild to moderate mental distress, testing for sexually transmitted diseases (STDs) or prescriptions of contraceptives. This kind of availability and the image of supplying lowthreshold services might create the opportunity for student welfare organizations to reach students and young adults in a way than cannot be matched by other institutions, and to overcome some of the barriers to help-seeking, including e.g., fear of stigma, financial constraints, lack of information about help and mental health services available, and time constraints $(27,28)$.

The regulation defining the purpose of student welfare organizations does not include a detailed description of services to be offered by the organization, other than its responsibility to ensure that students have access to the welfare services they are in need of. Hence, depending on campus size and location, the student welfare organization can to various degrees rely on existing services supplied by the local community. As a result, there is reason to believe that the health care services currently supplied by the student welfare organization vary considerably between organizations and campuses. If students experience on-campus health services as easily accessible and low-threshold compared with services in the local community, such variation might translate into differences in help-seeking and treatment. In particular, this might affect local and non-local students differently, due to differences in social network and information about the local services.

The aim of this study is to describe the use of health care services among students at Norwegian universities and colleges. Using student self-report data from The Students' Health and Well-being Study 2018 [Studentenes Helse- og Trivselsundersøkelse] (the SHoT 2018-study), we describe the prevalence of symptoms of mental health distress and helpseeking patterns in relation to gender, symptom severity, among local and non-local students and students from large vs. small Norwegian student welfare organizations. To complement the information on student health care service use, information about the supply of on-campus health care services is collected through semi-structured interviews with representatives from Norwegian student welfare organizations.

\section{MATERIALS AND METHODS}

\section{Setting and Participants-The SHoT-Study}

The SHoT-study is a Norwegian survey on mental and physical health, quality of life, health related behaviors and medication use among students in higher education, carried out over three waves in 2010, 2014, and 2018. In 2018, an invitation to participate was sent to all Norwegian full-time students (enrolled in Norwegian universities and colleges or studying abroad) in the age group 18-35. The study was conducted between February and April. The participation rate for the 2018 -survey was $31 \%$ (50,054 students), with higher relative participation for female students compared with male students $(4,29)$. 


\section{Variables/Measures of Student Characteristics and Mental Health}

All variables related to demographics, self-reported mental health, help-seeking, and use of health care services among students were obtained by from the SHoT-2018 study. The participants were asked about their gender, age and whether they considered themselves new in their study city (nonlocal students). The SHoT questionnaire included the Hopkins Symptoms Checklist (HSCL-25), a widely used screening instrument for psychological distress, mainly anxiety and depression symptoms $(12,30)$. It has been used in a variety of health care in general population settings and provide good screening performance and psychometric properties. An investigation of the factor structure based on the SHoT2014 dataset showed that a uni-dimensional model had the best psychometric properties in the student population and not the original subscales of anxiety and depression (31). Cronbach's alpha for the version of HSCL-25 used in the 2018 SHoT-survey is 0.94 .

In the HSCL-25 each question represents a claim relating to presence of a symptom of psychological distress and is answered on a 4 -item Likert scale from 1 (not at all) to 4 (extremely). The period of reference was the past 2 weeks. An average score above 1.75 is interpreted as an indication of moderate to severe symptoms of mental distress $(32,33)$, an average score above 2.0 as an indication of severe mental distress (34). The questions from the HSCL-25-list do not (on their own) provide sufficient foundation to make conclusions about an individual's mental health state, level of functioning, a psychiatric diagnosis or quality of life without a clinical evaluation. Finally, the participants were asked to rate their overall/general health (bad, not very good, good, very good)

\section{Use of and Satisfaction With Health Services}

Students were asked about their use of and satisfaction with health care services. The questions cover overall service use and frequency of use of general practitioner (GP), Out-ofhours GP, health clinic/nurse, and psychologist/psychotherapist, and whether these services were supplied by the local student welfare organization. Student health clinics mainly offer services related to physical and sexual health, such as testing for STDs and prescriptions of contraceptives, but also psychological counseling. Students reporting use of GP or Out-of-hours GP, were asked whether their visits the last 12 months were due to physical or mental health problems (yes/no on both). Satisfaction with health services was rated on a 1-5 scale (very dissatisfied, quite dissatisfied, neither/nor, quite satisfied, very satisfied). In our analyses, we have grouped "very satisfied" and "quite satisfied" into one combined category (satisfied) indicating satisfaction with local health care services.

\section{Missing Data}

In total, 50,054 students participated in the survey. However, some students did not answer all the questions covering our interest variables. Hence, our sample is therefore slightly smaller. Observations with missing information on student welfare organization membership, gender and age, where none of the 25 questions in the HSCL-25 list were answered, students from the smallest organization (with only 11 observations), and students with gender other than male/female were dropped from the sample from the SHoT-data. In total, this summed up to 2,576 students, leaving us with a sample of 47,478 student observations (94.9\% of the total number of respondents of 50,054) from 13 out of 14 Norwegian student welfare organizations. Further, some students did not answer the survey question asking whether they had moved to a new area when enrolling in higher education. Hence, in analyses comparing local and non-local students (students that had to move from their hometown to the University town/students considering themselves new to the city), the final sample consisted of 47,362 student observations ( $94.4 \%$ of the total number of respondents).

\section{Provision of Health Care Services Within Student Welfare Organizations}

Information about health care services offered by the student welfare organizations during the academic year 2017-2018 was obtained by the first author (MHS) from semi-structured telephone interviews with representatives from each organization, supplemented with information from the organizations' websites (one of the organizations was not available for interview). The interviews were conducted between December 11th 2020 and March 1st 2021. The interviews comprised questions on types of health care services offered by the student welfare organization, collaborations with local providers of health care, availability (location and waiting lists), and financing and user costs. Health services offered within student welfare organizations associations are free of change or heavily subsidized. Student welfare organizations were defined as either small ( $<20,000$ students) or large ( $>40,000$ students). All welfare associations could be classified according to these groups as none of them had between 20,000 and 40,000 members. Three out of four students were members of a large student welfare organizations. The small organizations had between 4,000 and 20,000 members. The size of the student welfare organizations mirrors the size of the universities and colleges located in the respective geographical area. Some student welfare organizations cover a very wide geographical area. The longest distance between two campuses within one organization amounts to over $800 \mathrm{~km}$ (the case in two organizations).

\section{Statistical Analysis}

Multivariate logistic regressions were used to estimate associations between binary outcomes indicating symptom pressure of mental distress or use of health care services and student characteristics (local vs. non-local students, students at large student welfare organizations vs. small organizations, and students with high vs. moderate-low levels of self-reported mental distress). All regressions were adjusted for age and sex, and standard errors were clustered at the student welfare organization level. All analyses were run using the Stata MP 15.1 software. 
TABLE 1 | Descriptive statistics: student characteristics, mental health and use of health care services: $N=47,478$.

\begin{tabular}{|c|c|c|c|}
\hline & Total & Female & Male \\
\hline \multicolumn{4}{|l|}{ Demographics } \\
\hline Female & $69.2 \%$ & & \\
\hline Age 18-22 & $49.4 \%$ & & \\
\hline Age 23-35 & $50.6 \%$ & & \\
\hline Moved to a new city to enter higher education & $67.0 \%^{\mathrm{a}}$ & $66.0 \%$ & $69.1 \%$ \\
\hline Belong to a large student welfare organization (\#students $>20,000$ ) & $66.8 \%$ & $66.8 \%$ & $66.9 \%$ \\
\hline \multicolumn{4}{|l|}{ Symptoms of mental distress } \\
\hline Average HSCL-25-score (cont. range 1-4) (standard deviation) & $1.73(0.549)$ & $1.82(0.555)$ & $1.53(0.481)$ \\
\hline Average HSCL-25-score $>2$ & $26.5 \%$ & $31.4 \%$ & $15.5 \%$ \\
\hline \multicolumn{4}{|l|}{ Use of health care services } \\
\hline Visited GP & $59.4 \%$ & $64.8 \%$ & $47.2 \%$ \\
\hline Use of out-of-hours GP & $12.6 \%$ & $13.7 \%$ & $10.2 \%$ \\
\hline For physical problems (GP/ER last 12 months) & $40.4 \%$ & $45.3 \%$ & $29.2 \%$ \\
\hline For mental problems (GP/ER last 12 months) & $15.0 \%$ & $17.6 \%$ & $9.0 \%$ \\
\hline Use of health clinic/nurse & $13.9 \%$ & $17.7 \%$ & $5.3 \%$ \\
\hline Help-seeking at psychologist/psychotherapist & $10.4 \%$ & $11.9 \%$ & $7.0 \%$ \\
\hline Satisfaction with local health care services ${ }^{b}$ & $64.9 \%$ & $66.0 \%$ & $62.5 \%$ \\
\hline
\end{tabular}

${ }^{a} N=47,362 ;{ }^{b}$ Includes both answers quite satisfied and very satisfied with local health care services.

\section{RESULTS}

\section{Student Characteristics and Use of Health Care Services in SHoT 2018}

Descriptive statistics on demographics, mental health and use of health care services for SHoT-2018 participants are shown in Table 1. The sample used in the below analyses consisted of 47,478 students. The proportion of female students was $69 \%$, and there were about equal shares of students aged 18-22 and 2335 . Two out of three students had moved to a new area or city when entering college or University, and the same proportion of students belonged to a large welfare organization.

The average score on the HSCL-25 questionnaire was 1.73 , with $26.5 \%$ of the students having an average score higher than 2 , indicting a severe symptom load. Reported symptoms of mental distress were notably higher in female than in male students. The average HSCL-25-scores were 1.82 and 1.53 and the share of students with an average score higher than 2 were 31.4 and $15.5 \%$, for female and male students, respectively.

Overall, about $60 \%$ of students had visited a GP and $13 \%$ had visited Out-of-hours GP located in the study city/region during the last 12 months. Forty percentage of the sample gave physical health problems and $15 \%$ reported mental health problems as the main reason for their visit(s) to the GP, Out-of-hours GP or emergency room at hospital (ER). A total of 6,592 students (13.9\%) reported to have consulted a health clinic or a nurse. Of these, only about $9 \%$ reported monthly (or more frequent) visits. Further, 4,937 students (10.4\%) had been to a psychologist/ psychotherapist, three out of four of these at least as frequently as once a month. All help-seeking patterns, but particularly use of health clinic/nurse and mental health services, were more common in female than male students explain. Two thirds of students reported to be quite or very satisfied with the local health care services, a slightly higher proportion in females compared to males (66.0 vs. $62.5 \%$ ).

Table 2 reports differences in use of health care services between non-local and local students, and between students in large and small student welfare organizations. Overall, the prevalence of self-reported symptoms of mental distress was similar in local and non-local students (OR $=0.95,95 \%$ CI $0.88-$ 1.02 ), and across students in large and small student welfare organizations $(0.90,95 \%$ CI $0.75-1.08)$.

\section{Health Service Use in Non-local vs. Local Students}

Non-local students were less likely to visit a GP or Out-of-hours GP in the community where they study, compared with local students (OR $=0.80,95 \%$ CI $0.67-0.95$, and $\mathrm{OR}=0.94,95 \%$ CI 0.89-0.99) (Table 2). Among those using these services, the reason for their visits (mental or physical health problems) did not differ between local and non-local students. The proportion of students that had visited a health clinic/nurse was about $60 \%$ higher, and use of psychotherapy $7 \%$ higher, among non-local compared to local students.

Non-local students used all services offered by the student welfare organization notably more than local students; they were about 2-3 times more likely to visit the health clinic/nurse and GP, and about $60 \%$ more likely to see a psychologist/psychotherapist when services were offered within the welfare organization, compared to local students.

\section{Health Service Use in Large vs. Small Student Welfare Organizations}

Students in large student welfare organizations had a $20 \%$ increased odds of using GPs in general and a 19-fold increased odds of having used GPs working for the student 


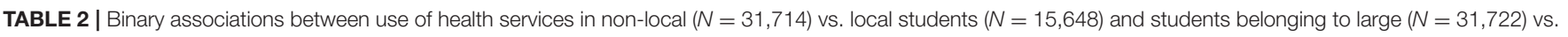
small $(N=15,756)$ student welfare organizations, presented as odds ratios.

\begin{tabular}{|c|c|c|c|c|}
\hline & \multicolumn{2}{|c|}{$\begin{array}{l}\text { Non-local students } \\
\text { (vs. local students) }^{\mathrm{a}}\end{array}$} & \multicolumn{2}{|c|}{$\begin{array}{l}\text { Student in large welfare organizations } \\
\text { (vs. small welfare organizations) }\end{array}$} \\
\hline & OR & $95 \% \mathrm{Cl}$ & OR & $95 \% \mathrm{Cl}$ \\
\hline Average HSCL-25-score>2 & 0.95 & $(0.88-1.02)$ & 0.90 & $(0.75-1.08)$ \\
\hline \multicolumn{5}{|l|}{ Use of health care services } \\
\hline Visited GP & 0.80 & $(0.67-0.95)$ & 1.21 & $(1.01-1.45)$ \\
\hline Use of out-of-hours GP & 0.94 & $(0.89-0.99)$ & 0.76 & $(0.63-0.92)$ \\
\hline For physical problems (GP/ER last 12 months) & 1.02 & $(0.95-1.09)$ & 1.20 & $(1.04-1.39)$ \\
\hline For mental problems (GP/ER last 12 months) & 1.05 & $(1.00-1.10)$ & 1.09 & $(0.96-1.26)$ \\
\hline Health clinic/nurse & 1.58 & $(1.39-1.80)$ & 0.66 & $(0.45-0.96)$ \\
\hline Psychologist or other therapist & 1.07 & $(1.03-1.12)$ & 1.27 & $(1.10-1.47)$ \\
\hline \multicolumn{5}{|c|}{ Use of student welfare organization health services } \\
\hline Visited GP & 3.12 & $(2.33-4.18)$ & 19.21 & $(8.35-44.17)$ \\
\hline Health clinic/nurse & 2.56 & $(2.14-3.06)$ & 0.69 & $(0.30-1.54)$ \\
\hline Psychologist/psychotherapist & 1.61 & $(1.48-1.75)$ & 1.58 & $(1.00-2.50)$ \\
\hline Satisfied with local health care services & 1.09 & $(0.99-1.21)$ & 2.01 & $(1.57-2.55)$ \\
\hline
\end{tabular}

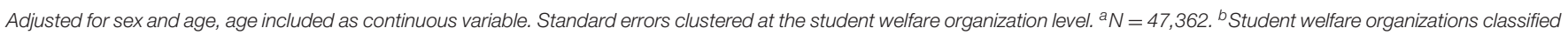
as large include the three largest in Norway.

welfare organizations, compared to students from small welfare organizations.

The use of health clinics was lower among students belonging to large student welfare organizations $(\mathrm{OR}=0.66,95 \% \mathrm{CI}$ 0.45-0.96), while the use of psychologist/psychotherapist was more frequent among students in large organizations $(\mathrm{OR}=$ 1.27, 95\% CI 1.10-1.47) compared to small. Looking at the use of mental health services supplied by the student welfare organizations, students at large organizations were about $60 \%$ more likely to visit psychologist/ psychotherapist than students in small organizations.

\section{Satisfaction With Health Services}

Table 2 shows that twice as many students in large welfare organizations were satisfied with their health services offered where they study, compared to small welfare organization students. Although statistical evidence was borderline, non-local students seemed slightly more satisfied with the services compared to local students $(\mathrm{OR}=1.09$, 95\% CI 0.99-1.21).

\section{Health Care Use in Students With High vs. Low-Moderate Symptom Load}

Students with symptoms of severe mental distress (average HSCL-25-score >2) used all types of health care services more frequently than other students, except for health clinics/nurses (Table 3). In particular, use of psychologist/psychotherapist, and GP, Out-of-hours GP, or ER due to mental health problems, was notably higher in this sub sample of students: Students with an average HSCL-25-score above 2 were 4-5 times more likely to use these services than other students, and 3 times more likely to receive mental health treatment (psychologist/ psychotherapist) at their student welfare organizations. However,
TABLE 3 | Binary associations between use of health services in students with high symptom load (avg. HSCL-25-score $>2)(N=12,576)$ vs. students with low-moderate symptom load of mental distress (avg. HSCL-25-score $\leq 2$ ) $(N=34,902)$, presented as odds ratios.

\begin{tabular}{|c|c|c|}
\hline & \multicolumn{2}{|c|}{$\begin{array}{l}\text { Students with high vs. } \\
\text { low-moderate symptom load of } \\
\text { mental distress }\end{array}$} \\
\hline & OR & $95 \% \mathrm{Cl}$ \\
\hline \multicolumn{3}{|l|}{ Use of health care services } \\
\hline Visited GP & 1.23 & $(1.19-1.28)$ \\
\hline Use of out-of-hours GP & 1.28 & $(1.22-1.36)$ \\
\hline $\begin{array}{l}\text { For physical problems (GP/ER last } \\
12 \text { months) }\end{array}$ & 1.38 & $(1.33-1.44)$ \\
\hline $\begin{array}{l}\text { For mental problems (GP/ER last } \\
12 \text { months) }\end{array}$ & 4.39 & $(4.10-4.69)$ \\
\hline Health clinic/nurse & 0.83 & $(0.76-0.89)$ \\
\hline Psychologist or other therapist & 5.00 & $(4.47-5.58)$ \\
\hline \multicolumn{3}{|c|}{ Use of student welfare organization health services } \\
\hline Visited GP & 1.12 & $(0.99-1.26)$ \\
\hline Health clinic/nurse & 0.81 & $(0.72-0.90)$ \\
\hline Psychologist/psychotherapist & 3.01 & $(2.71-3.35)$ \\
\hline $\begin{array}{l}\text { Satisfied with local health care } \\
\text { services }\end{array}$ & 0.62 & $(0.60-0.64)$ \\
\hline
\end{tabular}

Adjusted for sex and age, age included as continuous variable. Standard errors clustered at the student welfare organization level.

this group was less satisfied with health services than those with lower levels of psychological distress $(\mathrm{OR}=0.62$, 95\% CI 0.600.64). Among students with an average HSCL-25-score higher than 2 , about $50 \%$ reported to be in good health or in very good health. 
TABLE 4 | Supply of health care services in small and large student welfare organizations.

Student welfare organization size

Large ( $>40,000$ students) $N=3$

Small ( $\leq 20,000$ students) $N=10$

\section{Supplied within the student welfare organization \\ Counselor \\ Nurse/health clinic \\ Psychologist/psychotherapist \\ GP \\ Dentist \\ Supplied in the local region and made accessible through the student welfare organization \\ Nurse/health clinic \\ Psychologist/psychotherapist \\ GP \\ Student Welfare Organization Health Care Services}

$3 / 3100 \%$

$1 / 333 \%$

$3 / 3100 \%$

$1 / 333 \%$

$2 / 367 \%$

$2 / 367 \%$

$0 / 30 \%$

$2 / 367 \%$

\begin{abstract}
$10 / 10100 \%$
$5 / 1050 \%$

$6 / 1060 \%$

$0 / 100 \%$

$0 / 100 \%$

$6 / 1060 \%$

$2 / 1020 \%$

$0 / 100 \%$
\end{abstract}

Table 4 summarizes the supply of health care services in Norwegian student welfare organizations. Some differences in the supply of services across campuses (within the organization) exist; however, most organizations manage to offer a similar portfolio of services to all their students. Hence, differences in services available to students are a feature mainly between organizations, and not within. All Norwegian student welfare organizations had counselors offering advisory services for students seeking help for mild to moderate mental health problems. For three of the organizations, this was the only type of health service offered (not displayed in the table). The counselors were health workers, but not licensed therapists, such as psychologists or psychotherapists.

The three organizations classified as large had psychologists/psychotherapists on staff and offered mental health care services in addition to advisory services. This was only the case in $60 \%$ of the small organizations. Two of the small organizations offered mental health services (psychologist) in collaboration with the local community. Hence, three of the organizations classified as small had no mental health care for their students, internally or in collaboration with the local community.

\section{Physical and Sexual Health Care Services}

Health clinics/nurses were offered more frequently at small student welfare organizations, compared with large. However, in many organizations these services were made available in collaboration with the local community, leaving little difference in the actual supply between organizations and campuses. In many cases, municipality health clinics were perceived as integrated in the health care services provided by the student welfare organization due to a convenient location close to campus. Physical health services (GP and dental services) were only supplied at the large organizations, internally (in one case for GP, in two cases for dentist) or by private clinics located on campus (in two cases for GP).

\section{DISCUSSION}

\section{Main Findings}

In this large national study of more than 47,000 higher education students (SHoT, Norway) in 2018, levels of selfreported symptoms of mental distress and satisfaction with health services were similar in local and non-local students, and across student groups belonging to large and small student welfare organizations. Further, our results demonstrate how important low-threshold and easily accessible services provided by the student organizations are, particularly for non-local students. Students with high levels of anxiety and depression reported to use a wide range of health services, both on campus and community/hospital based, including Out-of-hours GP, and in particular, mental health care services. Further, we found evidence suggesting that differences in health care service preferences between students from large and small student welfare organizations. However, interviews with the organizations revealed that this simply mirrored the available services at the respective campuses and was not necessarily an indication of differences in student demand and preferences.

The share of female respondents has increased from 58 to $59 \%$ in the 2010- and 2014-waves of the study to $69 \%$ in the current sample. The 2010 and 2018 samples were similar with respect to the age distribution, with equal shares of respondents aged 18-22 and 23-35 years, while the 2014 sample had a slightly older student sample with $38 \%$ aged $18-22$. The share of students moving to a new area at University or college enrollment was stable over all three surveys $(34,35)$.

\section{Levels of Mental Distress in the Student Population}

As reported previously from the SHoT 2018 cohort, one in four students had an average HSCL-25-score above 2, indicating severe mental distress (12). This is in accordance with the prevalence presented in previous studies of similar populations $(18,36)$. Compared with the previous waves of the SHoT-survey from 2010 to 2014, this represents an increase in prevalence. In $201016 \%$ of students had an average HSCL-25-score higher than 2 , in 2014 the prevalence was $21 \%$ (4). The increase in the share 
of students experiencing symptoms of severe mental distress between 2010 and 2018 is found to be stronger in female than in male students (4). To add to the picture, we compared the HSCL25 -score with self-assessed global health. Among students with an average HSCL-25-score higher than 2, about 50\% reported to be in good health or in very good health. Hence, the average HSCL-25-score at the chosen cut-off level does only to some extent mirror global health.

\section{Use of Health Care Services in Different Student Populations}

Among the most well-known barriers to mental health help seeking are: male gender, stigma, poor availability and associated costs $(21,37)$. Our data confirmed the established gender ratio for help seeking, particularly for mental health problems. Previous studies on help-seeking among students suffering from mental distress have found that a large share do not seek and receive help, even when low-threshold campus-based services are available $(28,38)$. In contrast, our findings indicate that demand for mental health care was pronounced among these students, particularly non-local students. Although the comparison between large and small student welfare organizations might not be relevant for all countries, it should be of great concern how health care needs in students moving from their hometowns to a new area are met.

The majority-two thirds-of Norwegian students moved from home to a new city to study, a larger proportion than in other comparable western countries (39). We are not aware of any existing studies that have investigated use of health services across local and non-local domestic students. However, the importance of available mental health care for international students has been devoted attention (40). Further, it has been found that students living in campus housing were significantly more likely to use mental health service at their campus (psychotherapy) than students living off campus (41). Though this might show the significance of proximity to services offered or active gatekeeping practice rather than a relatively high demand for counseling among non-local students.

\section{Mental Distress Symptom Burden and Use of Health Care Services}

Use of all mental and physical health services, was markedly higher in those with an average HSCL-25-score above 2, the only exception was a $20 \%$ reduction in use of health clinic/nurse. Across health care settings, students with the highest symptom burden sought help from psychologists/therapists and GPs three to five times more often than those with a lower symptom burden. This, however, does not provide the foundation for concluding on the share of students with depression and anxiety seeking treatment for mental health problems. Previous studies report that most students with mental health problems do not seek and receive help (41), and that help-seeking patterns vary with types of mental health issues (42). We find that many students with psychological distress use student health care services, though we cannot conclude whether this represents a large share of the whole group of students who needs help.
The fact that students who experience the highest symptom burden and are most dependent on these services are less satisfied then healthier and less frequent users, is unfortunate and has been reported previously (43). Common/possible explanations include long waiting lists, unmet needs in therapy, and often the mental condition itself; depressed people, for example, often experience low energy and motivation, are generally pessimistic about their treatment and future outcomes. Nevertheless, it should always be a goal to reach out and accommodate students who struggle, in a way that call hope, trust, reduce stigma and strengthen adherence to the therapy. Students are particularly susceptible to discontinued follow up and therapy, because student life is full of interruptions; brakes, vacation, and studies abroad being some of them.

\section{Interviews With Student Welfare Organizations}

Student mental health treatment can be defined as integrated (offered by the student welfare organization on campus) or divided treatment (both on campus and in community or specialized health care), and referral to specialized health care outside campus (44). Interviews with Norwegian student welfare organizations showed that services offered in the academic year 2017-2018 varied substantially between organizations. In line with our findings, between-campus differences in use of health care services documented in the US context are also found to be related to services available, and not necessarily demand (41).

Further, the SHoT 2018 questionnaire did not specify whether the students had received individual, group therapy, or both. Personal interviews with employees at the student welfare organizations revealed that group based mental health initiatives where not commonly offered before SHoT 2018 yet have become increasingly implemented and popular among students after 2018. Therefore, we can assume that the majority of students who reported help seeking in SHoT 2018 mainly received individual counseling. Of note, group therapy has generally proven good efficacy and might be particularly useful for students; students are familiar with group situations, both in their social lives, living arrangements and academic group learning and exams (45). Group therapy is not only useful in students with psychiatric disorder or psychopathology, but helps improve general factors like autonomy, socialization, self-esteem, and improved interpersonal skills. Mindfulness has also been widely introduced on-campus. Making groups normative, easily accessible, and visible on campus has the potential to reduce stigma and include non-clinical populations. If successful, this might reduce isolation and hopelessness, which in turn might prevent depression (45). Changes in the health care services provided by student welfare organizations since 2018 are mainly related to expanding of group-based health promoting efforts, such as courses, lectures or events. Ten out of 13 organizations have invested heavily in their group-based services since 2018, an investment driven in large by student demand. Only two organizations have invested their funds solely in expanding their capacity in 1-to-1 therapy. 


\section{Strengths and Weaknesses}

The SHoT-study provides a large sample size compared with other existing student mental health and well-being studies and includes a wide range of background variables. Invitations to participate were sent to students at all Norwegian universities and student welfare organizations, and the final sample includes at least 400 observations from each organization and more than 1,000 observations from 10 of the 13 organizations included in this sample. However, the response rate is relatively modest (31\%), and we have little information on non-participants beyond age- and gender distribution, which may limit the generalizability of the findings.

Our study is based on self-report only, and the HSCL-25score included in our analysis does not indicate or reflect the total symptom burden or number of students with mental health problems and/or mental disorders. Similarly, use of health services obtained by national register linkage would have provided more accurate estimates of off campus service use. In addition, information on psychotropic drug use could shed further light on students' preferences when it comes to dealing with mental health problems. This is, however, outside the scope of this study and will be covered separately in other studies using the SHoT data set. Finally, it should be kept in mind that the recall period for self-reported symptoms of mental distress was 2 weeks, while the recall period for use of health services was 12 months when reading our results.

The SHoT-survey asks students about their use of GP, nurse/health clinic and psychologist/psychotherapists, but not specifically advisory services with counselors without formal license as therapists. Hence, a prominent part of the student welfare organizations' supply did not have a specific category in the SHoT questionnaire. In some cases, students who have seen counselors might have thought of this as seeking help from a therapist or a nurse, potentially giving rise to measurement errors. In addition, collaboration between local health care services and student welfare organizations is common. Some student welfare organizations provide office space for municipality health clinics or GPs on campus and keep user costs low by subsidizing. Therefore, it is not always clear to the student weather whether services are offered by the student welfare organization, a community or specialized clinic. Hence, local public or private services might appear as run by the student welfare organization, suggesting a potential source of measurement errors in reported use of services.

In conclusion, we argue that this study offers new and relevant results from a large-scale student health and well-being survey, well-suited to inform health promotion, new prevention and treatment models offered by student welfare organizations and municipalities hosting University students. Further, there seems to be an urgent need to discuss the structure, organization and

\section{REFERENCES}

1. Auerbach RP, Alonso J, Axinn WG, Cuijpers P, Ebert DD, Green JG, et al. Mental disorders among college students in the world health financing of these services across Norwegian universities and campuses. Particularly, the high proportion of non-local students are dependent on well-functioning low-threshold services on campus, offered by student welfare organizations. Finally, more rigorous research and evaluations need to be carried out simultaneously with new student health services and initiatives, both in Norway and globally.

\section{DATA AVAILABILITY STATEMENT}

The data analyzed in this study is subject to the following licenses/restrictions: The datasets for this article are not publicly available because of privacy regulations from the Norwegian Regional Committees for Medical and Health Research Ethics (REC). Approval from REC (https://helseforskning.etikkom. no) is a pre-requirement. Guidelines for access to SHoT data are found at https://www.fhi.no/en/more/access-to-data. Requests to access these datasets should be directed to Børge Sivertsen, borge.sivertsen@fhi.no.

\section{ETHICS STATEMENT}

The SHoT 2018 was approved by the Regional Committee for Medical and Health Research Ethics in Western Norway (no. 2017/1176). Electronic informed consent was obtained after complete description of the study to the participants. The patients/participants provided their written informed consent to participate in this study.

\section{AUTHOR CONTRIBUTIONS}

MS and OB contributed substantially to the conceptualization and design of the study. BS was the main investigator and responsible for data collection, data storage, and ethical approval in SHoT 2018. MS performed the statistical analysis and wrote the first draft of the manuscript. BS and OB revised it critically. All authors read and approved the final version of the manuscript and contributed to the interpretation of the data.

\section{FUNDING}

SHoT 2018 has received funding from the Norwegian Ministry of Education and Research (2017) and the Norwegian Ministry of Health and Care Services (2016).

\section{ACKNOWLEDGMENTS}

We wish to thank all participating students as well as the three largest student associations in Norway ( $\mathrm{SiO}$, Sammen, and $\mathrm{SiT}$ ), who initiated and designed SHoT studies. organization world mental health surveys. Psychol Med. (2016) 46:295570. doi: 10.1017/S0033291716001665

2. Auerbach RP, Mortier P, Bruffaerts R, Alonso J, Benjet C, Cuijpers P, et al. WHO world mental health surveys international college student project: 
prevalence and distribution of mental disorders. J Abnorm Psychol. (2018) 127:623-38. doi: 10.1037/abn0000362

3. Gunnell D, Kidger J, Elvidge H. Adolescent mental health in crisis. BMJ. (2018) 361:k2608. doi: 10.1136/bmj.k2608

4. Sivertsen B, Rakil H, Munkvik E, Lonning KJ. Cohort profile: the SHoT-study, a national health and well-being survey of Norwegian University students. BMJ Open. (2019) 9:e025200. doi: 10.1136/bmjopen-2018-025200

5. Kessler RC, Amminger GP, Aguilar-Gaxiola S, Alonso J, Lee S, Ustun TB. Age of onset of mental disorders: a review of recent literature. Curr Opin Psychiatry. (2007) 20:359-64. doi: 10.1097/YCO.0b013e32816ebc8c

6. Kessler RC, Berglund P, Demler O, Jin R, Merikangas KR, Walters EE. Lifetime prevalence and age-of-onset distributions of DSM-IV disorders in the national comorbidity survey replication. Arch Gen Psychiatry. (2005) 62:593-602. doi: 10.1001/archpsyc.62.6.593

7. Bewick B, Koutsopoulou G, Miles J, Slaa E, Barkham M. Changes in undergraduate students' psychological well-being as they progress through University. Stud High Educ. (2010) 35:633-45. doi: 10.1080/03075070903216643

8. Bewick BM, Gill J, Mulhearn B, Barkham M, Hill AJ. Using electronic surveying to assess psychological distress within the UK student population: a multi-site pilot investigation. E J Appl Psychol. (2008) 4:1-5. doi: 10.7790/ejap.v4i2.120

9. Broglia E, Millings A, Barkham M. The counseling center assessment of psychological symptoms (CCAPS-62): acceptance, feasibility, and initial psychometric properties in a UK student population. Clin Psychol Psychothera. (2017) 24:1178-88. doi: 10.1002/cpp.2070

10. Bayram N, Bilgel $\mathrm{N}$. The prevalence and socio-demographic correlations of depression, anxiety and stress among a group of University students. Soc Psychiatry Psychiatr Epidemiol. (2008) 43:667-72. doi: 10.1007/s00127-008-0345-x

11. Ballester L, Alayo I, Vilagut G, Almenara J, Cebrià AI, Echeburúa E, et al. Mental disorders in Spanish University students: prevalence, age-of-onset, severe role impairment and mental health treatment. J Affect Disord. (2020) 273:604-13. doi: 10.1016/j.jad.2020.04.050

12. Knapstad M, Sivertsen B, Knudsen AK, Smith ORF, Aarø LE, Lønning $\mathrm{KJ}$, et al. Trends in self-reported psychological distress among college and University students from 2010 to 2018. Psychol Med. (2021) 51:4708. doi: 10.1017/S0033291719003350

13. Berger H, Franke GH, Hofmann F-H, Sperth M, Holm-Hadulla RM. Mental health of students and its development between 1994 and 2012. Ment Health Prevent. (2015) 3:48-56. doi: 10.1016/j.mhp.2015.01.001

14. Verger P, Guagliardo V, Gilbert F, Rouillon F, Kovess-Masfety V. Psychiatric disorders in students in six French universities: 12-month prevalence, comorbidity, impairment and help-seeking. Soc Psychiatry Psychiatr Epidemiol. (2010) 45:189-99. doi: 10.1007/s00127-009-0055-z

15. Källoff K, Thomas A, Wahlgren L, Andersson C. Hur Mår Våra Studenter? Studenthälsans Undersökning Om Studiemiljö, Psykisk Hälsa, Alkohol Och Drogvanor Samt Sexuell Hälsa Hos Malmö Högskolas Studenter. Malmö: Högskola (2015).

16. Folkhälsamyndigheten. Psykisk Ohälsa Bland HögskoleOch Universitetsstudenter Kan Förebyggas 2018. Østersund: Folkhälsomyndigheten (2018).

17. Rückert H-W. Students? mental health and psychological counselling in Europe. Ment Health Prevent. (2015) 3:34-40. doi: 10.1016/j.mhp.2015.04.006

18. Ibrahim AK, Kelly SJ, Adams CE, Glazebrook C. A systematic review of studies of depression prevalence in University students. J Psychiatr Res. (2013) 47:391-400. doi: 10.1016/j.jpsychires.2012.11.015

19. Eisenberg D, Speer N, Hunt JB. Attitudes and beliefs about treatment among college students with untreated mental health problems. Psychiatr Serv. (2012) 63:711-3. doi: 10.1176/appi.ps.201100250

20. Ebert DD, Mortier P, Kaehlke F, Bruffaerts R, Baumeister H, Auerbach RP, et al. Barriers of mental health treatment utilization among first-year college students: first cross-national results from the WHO world mental health international college student initiative. Int J Methods Psychiatr Res. (2019) 28:e1782. doi: 10.1002/mpr.1782

21. Hunt J, Eisenberg D. Mental health problems and help-seeking behavior among college students. J Adolesc Health. (2010) 46:3-10. doi: 10.1016/j.jadohealth.2009.08.008
22. Eisenberg D. Countering the troubling increase in mental health symptoms among U.S. college students. J Adolesc Health. (2019) 65:573-4. doi: 10.1016/j.jadohealth.2019.08.003

23. Brown JSL. Student mental health: some answers and more questions. J Ment Health. (2018) 27:193-6. doi: 10.1080/09638237.2018.1470319

24. Kutcher S, Wei Y. School mental health: a necessary component of younth mental health policy and plans. World Psychiatry. (2020) 19:1745. doi: $10.1002 /$ wps. 20732

25. Cuijpers P, Auerbach RP, Benjet C, Bruffaerts R, Ebert D, Karyotaki E, et al. The world health organization world mental health international college student initiative: an overview. Int J Methods Psychiatr Res. (2019) 28:e1761. doi: 10.1002/mpr.1761

26. Forskrift om studentsamskipnader fra Kunnskapsdepartementet fra. FOR2008-07-22-828 (2008).

27. Eisenberg D, Downs MF, Golberstein E, Zivin K. Stigma and help seeking for mental health among college students. Med Care Res Rev. (2009) 66:52241. doi: $10.1177 / 1077558709335173$

28. Eisenberg D, Golberstein E, Gollust SE. Help-Seeking and access to mental health care in a University student population. Med Care. (2007) 45:594601. doi: 10.1097/MLR.0b013e31803bb4c1

29. Knapstad M, Heradstveit O, Sivertsen B. Studentenes Helse- Og Trivselsundersøkelse2018 (Students' Health and Wellbeing Study 2018). Oslo: $\mathrm{SiO}$ (Studentsamskipnaden i Oslo og Akershus) (2018).

30. Derogatis LR, Lipman RS, Rickels K, Uhlenhuth EH, Covi L. The hopkins symptom checklist (HSCL): a self-report symptom inventory. Behav Sci. (1974) 19:1-15. doi: 10.1002/bs.3830190102

31. Skogen JC, Øverland S, Smith ORF, Aarø LE. The factor structure of the hopkins symptoms checklist (HSCL-25) in a student population: a cautionary tale. Scand J Public Health. (2017) 45:357-65. doi: 10.1177/1403494817700287

32. Winokur A, Winokur DF, Rickels K, Cox DS. Symptoms of emotional distress in a family planning service: stability over a four-week period. Br J Psychiatry. (1984) 144:395-9. doi: 10.1192/bjp.144.4.395

33. Tambs K, Moum T. How well can a few questionnaire items indicate anxiety and depression? Acta Psychiatr Scand. (1993) 87:364-7. doi: 10.1111/j.1600-0447.1993.tb03388.x

34. Nedregård T, Olsen R. Studentenes Helse- og Trivselsundersøkelse SHOT 2014 Oslo: TNS Gallup (2014).

35. Nedregård T, Olsen R. Studentenes Helse- Og Trivselsundersøkelse SHOT 2010 Oslo: TNS Gallup (2010).

36. Hope V, Henderson M. Medical student depression, anxiety and distress outside North America: a systematic review. Med Educ. (2014) 48:96379. doi: $10.1111 /$ medu. 12512

37. D'Amico N, Mechling B, Kemppainen J, Ahern NR, Lee J. American college students' views of depression and utilization of on-campus counseling services. J Am Psychiatr Nurs Assoc. (2016) 22:302-11. doi: 10.1177/1078390316648777

38. Goodwin J, Behan L, Kelly P, McCarthy K, Horgan A. Help-seeking behaviors and mental well-being of first year undergraduate University students. Psychiatry Res. (2016) 246:129-35. doi: 10.1016/j.psychres.2016.09.015

39. Williams T. It's Cheaper to Live at Home While Attending College. So Why Are Fewer Students Doing It? (2021). Available online at: https://www.goodcall. $\mathrm{com} /$ news/its- cheaper-to-live-at-home-while-attending-college-so-whyare-fewer-students-doing-it-02085/ (accessed March 17, 2021).

40. Mori SC. Addressing the mental health concerns of international students. $J$ Counsel Dev. (2000) 78:137-44. doi: 10.1002/j.1556-6676.2000.tb02571.x

41. Eisenberg D, Hunt J, Speer N, Zivin K. Mental health service utilization among college students in the United States. J Nerv Ment Dis. (2011) 199:3018. doi: 10.1097/NMD.0b013e3182175123

42. Bourdon JL, Moore AA, Long EC, Kendler KS, Dick DM. The relationship between on-campus service utilization and common mental health concerns in undergraduate college students. Psychol Serv. (2020) 17:118-26. doi: 10.1037/ser0000296

43. Jackson JL, Chamberlin J, Kroenke K. Predictors of patient satisfaction. Soc Sci Med. (2001) 52:609-20. doi: 10.1016/S0277-9536(00)00 164-7

44. Iarovici D. The Nontraditional Student. Mental Health Issues and the University Student. Baltimore, MD: Johns Hopkins Univeristy Press (2014) 187-96p. 
45. Iarovici D. Models of Treatment. Mental Health Issues and the University Student. Baltimore, MD: Johns Hopkins Univeristy Press (2014) 197-204p.

Conflict of Interest: The authors declare that the research was conducted in the absence of any commercial or financial relationships that could be construed as a potential conflict of interest.

Publisher's Note: All claims expressed in this article are solely those of the authors and do not necessarily represent those of their affiliated organizations, or those of the publisher, the editors and the reviewers.
Any product that may be evaluated in this article, or claim that may be made by its manufacturer, is not guaranteed or endorsed by the publisher.

Copyright $\odot 2021$ Seether, Sivertsen and Bjerkeset. This is an open-access article distributed under the terms of the Creative Commons Attribution License (CC BY).

The use, distribution or reproduction in other forums is permitted, provided the original author(s) and the copyright owner(s) are credited and that the original publication in this journal is cited, in accordance with accepted academic practice. No use, distribution or reproduction is permitted which does not comply with these terms. 